\title{
The pharmacogenomics of pain management: prospects for personalized medicine
}

\author{
This article was published in the following Dove Press journal: \\ Journal of Pain Research \\ 10 February 2016 \\ Number of times this article has been viewed
}

\author{
Sonya Ting' \\ Stephan Schug ${ }^{2,3}$ \\ 'Department of Anaesthesia, Sir \\ Charles Gairdner Hospital, Perth, \\ WA, Australia; ${ }^{2}$ Anaesthesiology Unit, \\ School of Medicine and Pharmacology, \\ University of Western Australia, \\ Perth, WA, Australia; ${ }^{3}$ Department of \\ Anaesthesia and Pain Medicine, Royal \\ Perth Hospital, University of Western \\ Australia Anaesthesiology Unit, Royal \\ Perth Hospital, Perth, WA, Australia
}

Correspondence: Stephan Schug UWA Anaesthesiology Unit, Level 2, MRF Building G Block, Royal Perth Hospital, GPO Box X2213, Perth, WA 6847, Australia

Tel +6I 892240201

Fax +6I 892240279

Email stephan.schug@uwa.edu.au

\begin{abstract}
Pain is a common symptom that can be complex to treat. Analgesic medications are the mainstay treatment, but there is wide interindividual variability in analgesic response and adverse effects. Pharmacogenomics is the study of inherited genetic traits that result in these individual responses to drugs. This narrative review will attempt to cover the current understanding of the pharmacogenomics of pain, examining common genes affecting metabolism of analgesic medications, their distribution throughout the body, and end organ effects.
\end{abstract}

Keywords: cytochrome P450, COMT, pharmacokinetics, pharmacodynamics, inherited traits

\section{Introduction}

Pain is the most common presenting physical symptom in medicine and accounts for a substantial burden to the individual patient, health care, and society in general. Chronic pain, often defined as pain lasting more than 12 weeks, is a major worldwide issue with a prevalence of up to $34 \% .{ }^{1}$ Chronic pain is often difficult to manage, even for experienced clinicians, and has a significant detrimental impact on the quality of life and level of functioning for affected individuals. ${ }^{1}$ The monetary cost of managing chronic pain is immense, estimated at over US\$600 billion in the US annually and over US\$34 billion annually in Australia., ${ }^{2,3}$ Despite this growing problem, the provision of specialized pain services remains under-resourced. Even in first-world countries, less than $10 \%$ of people with chronic noncancer pain gain access to care, despite the fact that current knowledge might allow $80 \%$ to be treated effectively given adequate access to pain services. ${ }^{3}$ One of the major arms of pain management is the use of medications, including opioids and nonopioids. However, due to wide interindividual variability in therapeutic response and adverse effects, it can be time consuming to find the right medication and dose for individual patients, and occasionally hazardous for certain patients.

Pharmacogenomics is the study of the inherited genetic differences that result in individual responses to drugs. There is increasing recognition that inherited differences in drug targets and metabolism may have a marked influence on the heterogeneous response to drug therapy, potentially even more so than clinical variables such as age and organ function. ${ }^{4}$

Pharmacogenomics has the potential to improve pain management by predicting the individual response to a specific analgesic before initiation of therapy and therefore to streamline the way physicians prescribe medications to the individual. For instance, a noninvasive saliva test may one day allow clinicians to determine if a particular medication would be efficacious or have adverse effects, and provide guidance on 
individualized dosages. ${ }^{1}$ Pharmacogenomics may also result in improved drug development, testing, and registration, reducing the time from chemical synthesis to introduction into clinical practice, and therefore the overall cost of the drug development process. ${ }^{5}$

With increases in our understanding of genetics-associated drug responses and increased availability of cheaper genetic testing, pharmacogenomics is becoming increasingly incorporated into clinical decision making. However, pharmacogenomics research in pain management has lagged behind efforts in other areas of medicine. The reasons for this are multiple. Pain and analgesia are complex, and their experience is considered to be subjective and highly variable. This variability is influenced by many factors including differences in the degree of pain stimulation and sensitivity, variation in pain perception, psychological factors, sociocultural factors, prior opioid use, age, sex, weight, and environmental influences. ${ }^{6}$ It can be challenging to identify the extent to which a drug response is influenced solely due to genetic differences.

Despite the challenges, the pursuit of personalized medicine is an understandably attractive goal, and one that has garnered attention from both physicians and pharmaceutical industries alike. The realm of pharmacogenomics is rapidly evolving, with genetic variations identified at almost every stage of drug kinetics and dynamics. As the human genome becomes more readily accessible, so the quest for tailored prescription and new drug targets continues to exponentially expand.

\section{Materials and methods}

The purpose of this narrative review article is to examine the current range of genetic variants with regard to pain and analgesia and to comment on the potential prospects for personalized medicine. A literature search was conducted using the National Library of Medicine database PubMed, using search terms "pharmacogenomics", "genetic polymorphisms", or "single nucleotide variants", and combining with "pain management", "analgesia", "single gene pain disorder", "pain genome wide association study", or "opioid metabolism". Later, this was limited to articles specifically examining "CYP2D6", "CYP2C9", "cytochrome P450”, “ABCB1”, “UGT”, “OPRM1”, “COX”, “OPRK1”, "OPRD1", “COMT”, or "serotonin plasma membrane transport proteins". Our focus was on English-language articles relevant to the adult human population and without restraint for the year of publication. Our initial search yielded 482 articles of which 104 were review articles. The abstracts of all papers were reviewed and those that appeared to be relevant were included for review. Any referenced articles that appeared to be of relevance and not found within the original search parameters were also reviewed.

\section{History}

The recognition of inherited responses to drugs dates back to $510 \mathrm{BC}$, when Pythagoras noted that the ingestion of fava beans resulted in a potentially fatal reaction in some, but not all, individuals. ${ }^{5}$ His keen observation was later validated in 1957, when Browne identified that antimalarial drugs (that were derived from fava beans) could precipitate hemolytic anemia in susceptible individuals who had inherited the X-linked glucose-6-phosphate deficiency. ${ }^{7}$ Another notable example of inheritable differences in drug effects was noted in the $1950 \mathrm{~s}$, where the relationship between prolonged muscle relaxation after suxamethonium administration was linked to an inherited deficiency of plasma cholinesterase. ${ }^{4}$ This established a genetic cause for suxamethonium apnea, allowing anesthetists to improve management for patients with this potentially fatal condition.

In the late $1980 \mathrm{~s}$, the polymorphic human gene encoding the drug metabolizing enzyme CYP2D6 was cloned and characterized. ${ }^{8}$ Since the sequencing of CYP2D6, genes involved in many other pharmacogenetic traits have been isolated, and their clinical importance have been more clearly defined.

The Human Genome Project, which was first proposed in 1984, is the world's largest collaborative biological project. ${ }^{4}$ The researchers involved set out to determine the sequence of chemical base pairs that make up human DNA and to identify and map every gene within the human genome from a physical and functional standpoint. Since this was accomplished in 2003, the study of the human genome and interest in relevant fields such as pharmacogenomics has risen exponentially. ${ }^{9,10}$ As modern genome tests become increasingly accessible, we may be able to unravel the polygenic components of pain sensation and analgesic response mechanisms.

Studies involving pain genetics have identified many variations that influence almost every stage of pharmacokinetics and pharmacodynamics of analgesic agents.

\section{Genetics of drug metabolism}

The cytochrome P450 (CYP) enzyme system is a group of proteins responsible for drug metabolism whose biosynthesis is controlled by a large superfamily of genes. ${ }^{11,12}$ It is involved in the metabolism of over $90 \%$ of current therapeutic drugs, including analgesic agents. There have been 57 CYP genes identified in humans thus far. ${ }^{13}$ These genes are all highly polymorphic, and this contributes to the vast 
interindividual differences in drug metabolism. ${ }^{6}$ The genetic variants involved in CYP2D6 and CYP2C9 production have particular consequences in pain management.

\section{CYP2D6}

Located on chromosome 22q13.1, the gene encoding the enzyme CYP2D6 is one of the most widely investigated with relation to genetic polymorphism. ${ }^{8}$ It is responsible for the metabolism of around one-quarter of all currently marketed drugs, including common analgesics such as codeine, tramadol, and dihydrocodeine. Currently, more than 80 allelic variants have been reported for CYP2D6. ${ }^{14} \mathrm{~A}$ combination of polymorphisms, including single-nucleotide polymorphisms (SNPs), duplications, insertion/deletions, and/or gene conversions have been reported to affect CYP2D6 activity. ${ }^{11}$

The phenotypic variation of CYP2D6 due to genetic polymorphism is well established. Depending on their CYP2D6 function, patients can be categorized into poor metabolizers, intermediate metabolizers, extensive metabolizers, or ultrarapid metabolizers. The function is directly related to the number of normal (wild-type) or abnormal alleles inherited. ${ }^{12}$ The distribution of the CYP2D6 phenotypes varies by ethnicity (Table 1), largely due to differences in inherited SNPs. ${ }^{15,16}$ For example, the CYP2D6*4, CYP2D6*10, and CYP2D6*17 alleles have reduced activity and these alleles are expressed in a higher proportion, resulting in a higher incidence of poor metabolizer and intermediate metabolizer phenotypes. ${ }^{8,10}$

Knowledge of a patient's CYP2D6 phenotype can guide appropriate analgesic dosage and reduce the number of adverse reactions (Table 2) ${ }^{16}$ There are many case reports citing examples where failure to recognize these phenotypes resulted in life-threatening adverse reactions. ${ }^{17-19}$ Many of these cases involved the administration of codeine to ultrarapid metabolizers, who subsequently experienced respiratory or central nervous system depression. The pediatric population is known to be particularly susceptible. ${ }^{17} \mathrm{~A}$ recent case report documented

Table I Incidence of the CYP2D6 enzyme phenotypes among different ethnic populations

\begin{tabular}{lllll}
\hline Phenotype & Caucasian, \% & $\begin{array}{l}\text { Ethiopian/ } \\
\text { Nigerian, \% }\end{array}$ & Asian, \% & Hispanic, \% \\
\hline $\begin{array}{l}\text { Poor } \\
\text { metabolizer }\end{array}$ & $3-10$ & I.8-8.I & $0-1.2$ & $2.2-6.6$ \\
$\begin{array}{l}\text { Intermediate } \\
\text { metabolizer }\end{array}$ & I-2 & N/A & 5 I & N/A \\
$\begin{array}{l}\text { Ultrarapid } \\
\text { metabolizer }\end{array}$ & $0.8-4.3$ & 29 & 0.9 & 1.7 \\
\hline
\end{tabular}

Abbreviation: N/A, not available.
Table 2 The effects on metabolism and the potential clinical consequences of CYP2D6 variable phenotypes

\begin{tabular}{lll}
\hline Phenotype & Effect & Potential consequences \\
\hline $\begin{array}{l}\text { Poor } \\
\text { metabolizer }\end{array}$ & $\begin{array}{l}\text { Slower drug } \\
\text { metabolism }\end{array}$ & $\begin{array}{l}\text { Slower conversion to active } \\
\text { metabolites. } \\
\text { Increased risk of drug interactions } \\
\text { and adverse events. } \\
\text { Increased rate of drug elimination. }\end{array}$ \\
$\begin{array}{l}\text { Ultrarapid } \\
\text { metabolizer }\end{array}$ & $\begin{array}{l}\text { Faster drug } \\
\text { metabolism }\end{array}$ & Potentially lower drug efficacy. \\
\hline
\end{tabular}

respiratory depression in a pediatric ultrarapid metabolizer following the administration of tramadol, despite tramadol only being a partial opioid. ${ }^{18}$ In a study of dose adjustment of nortriptyline, a drug commonly prescribed in the management of chronic pain, it was calculated that the therapeutic dose for a CYP2D6 poor metabolizer would be tenfold less than for an ultrarapid metabolizer to achieve the same plasma levels. ${ }^{19}$

\section{CYP2C9}

Many nonsteroidal anti-inflammatory drugs (NSAIDs) are metabolized by the cytochrome CYP2C9. The gene coding for CYP2C9 is highly polymorphic, with over 50 variants identified. ${ }^{20}$ Two frequent allelic variants, CYP2C $9 * 2$ and CYP2C9*3, are found in poor metabolizers. The incidence of poor metabolizers is highest in the Caucasian population (Table 3). ${ }^{21,22}$

CYP2C9 polymorphism may play a significant role in NSAID toxicity. Poor metabolizers have reduced CYP2C9 activity compared to wild-type, resulting in reduced NSAID clearance, increased area under the plasma drug concentrationtime curve, and possibly an increased risk of adverse effects, although this is controversial. ${ }^{23}$ Case reports of patients treated with celecoxib showed that CYP2C $9 * 3$ homozygous patients had seven to ten times lower apparent clearance compared to patients with wild-type CYP2C9. ${ }^{24,25}$ A number of studies have also demonstrated a higher frequency of CYP2C $9 * 2$ and CYP2C9*3 in individuals who present with gastrointestinal bleeding following NSAID therapy. ${ }^{23,26}$

\section{Cytochrome drug interactions}

Many drugs increase or decrease the activity of CYP isoenzymes, resulting in clinically significant drug-drug interactions (Table 4). ${ }^{27}$ For example, apart from NSAID

Table 3 Allele frequencies of CYP2C9 polymorphism

\begin{tabular}{lllll}
\hline & $\begin{array}{l}\text { African- } \\
\text { American, \% }\end{array}$ & $\begin{array}{l}\text { Black- } \\
\text { African, \% }\end{array}$ & Asian, \% & Caucasian, \% \\
\hline CYP2C9*2 & 2.9 & $0-4.3$ & $0-0.1$ & $8-19$ \\
CYP2C9*3 & 2.0 & $0-2.3$ & $1.1-3.6$ & $3.3-16.2$ \\
\hline
\end{tabular}


Table 4 Medicines used in pain management as substrates of CYP

\begin{tabular}{lllll}
\hline 2D6 & 3A4 & 2C9 & 2B6 & 2C19 \\
\hline Codeine & Fentanyl & lbuprofen & Methadone & Ketamine \\
Tramadol & Buprenorphine & Celecoxib & & \\
Oxycodone & & & \\
Hydrocodone & & & \\
Amitriptyline & & & \\
Nortriptyline & & & \\
Venlafaxine & & & \\
\hline
\end{tabular}

Note: Data extracted from Indiana University Drug Interaction (http://medicine.iupui.edu/clinpharm/DDIs/ClinicalTable.aspx) and Genelex web site (Oesterheld J. Cytochrome P-450 (CYP) Metabolism Reference Table [http://genelex.com/clinical-guidance/cytochrome-p450-drug-interactions-table/]).

metabolism, CYP2C9 is also heavily involved in the metabolism of warfarin. Allelic variants may slow metabolism and prolong its action, resulting in a compounded effect on bleeding risk when prescribed with NSAIDs. Patients with the CYP2C9*2 or CYP2C9*3 genotypes taking both NSAIDs and warfarin have been shown to have significantly elevated prothrombin time, compared to patients with the wild-type variant. ${ }^{28}$

\section{P-glycoprotein transporter $A B C B$ I}

The P-glycoprotein transporter ABCB1 is an ATP-dependent efflux transporter present in a variety of human tissues, including the gastrointestinal tract, kidney, liver, and brain. It is involved in the transport of a broad range of drug substrates and influences their plasma levels. It is coded by the highly polymorphic $A B C B 1$ gene, which has 38 identified SNPs. ${ }^{29}$

One P-glycoprotein substrate is the prototypical opioid analgesic morphine. The effects of morphine are mediated by $\mu$-opioid receptors located in the brainstem and particularly in the medulla. P-glycoproteins in brain capillary endothelial cells act as outward transporters for morphine across the blood-brain barrier, thereby influencing cerebrospinal fluid (CSF) morphine concentrations. ${ }^{30}$

The C3435T (rs 1045642) allelic variant of ABCB1 reduces P-glycoprotein transporter function, resulting in increased CSF morphine concentrations. ${ }^{31}$ This variant has been associated with significant differences in interindividual pain relief achieved by morphine in 145 cancer patients. ${ }^{29}$ Another study found that individuals with C3435T and G2677T/A variant alleles reported an increased antinociceptive effect from oxycodone. ${ }^{32}$

The respiratory depressive effects of morphine are also thought to be mediated by central nervous system $\mu$-opioid receptors. The $\mathrm{C} 3435 \mathrm{~T}$ variant has been associated with increased respiratory depressive effects of fentanyl in Korean and Turkish adult patients. ${ }^{33,34} \mathrm{~A}$ recent study involving
American pediatric patients showed a significant association between ABCB1 61 (rs9282564) polymorphism and postoperative respiratory depression, but not with the $\mathrm{C} 3435 \mathrm{~T}$ variant. ${ }^{35} \mathrm{~A}$ contradictory result was noted in a separate study, which showed patients with variant alleles had a lower frequency of adverse drug reactions, such as nausea and itching. Patients with combined wild-type genotype of 3435CC and 2677GG had significantly more adverse reactions. A possible explanation is the studied adverse reactions are affected by plasma opioid concentrations rather than CSF concentrations which appear to be associated with respiratory depression. ${ }^{32}$

\section{Uridine diphosphate glucuronosyltransferase}

Uridine diphosphate glucuronosyltransferase (UGT) encompasses a group of phase II enzymes that are widely distributed throughout the human body and are involved in glucuronidation conjugation reactions. Morphine is primarily metabolized by UGT2B7 in the liver into two metabolites: morphine-3glucuronide (M3G) and morphine-6-glucuronide (M6G). ${ }^{36}$ M3G is the major metabolite (90\%) but does not confer an analgesic effect and may cause stimulatory effects such as allodynia, myoclonus, and seizure. The minor metabolite M6G $(10 \%)$ is a potent analgesic, but has poor permeability through the blood-brain barrier. When administered intravenously, it has a slower onset but longer duration of action compared to morphine, and has lower rates of adverse effects. ${ }^{37}$

A number of UGT polymorphisms have been investigated. One small trial involving neonates investigated the UGT2B7 $900 \mathrm{G}>$ A SNP. The 900A allele is thought to confer greater UGT activity over the wild-type $900 \mathrm{G}$ allele. The investigators found that $900 \mathrm{~A}$ carriers had relatively lower plasma morphine levels and higher M3G:morphine metabolic ratios, compared to wild-type..$^{38}$ These results suggest that patients with wild-type $900 \mathrm{G} / \mathrm{G}$ have lower morphine glucuronidation rates and possibly respond better 
to morphine with lower adverse effects. Another trial, involving 37 Japanese cancer patients and investigating the $802 \mathrm{C}>\mathrm{T}$ SNP, found that patients with $\mathrm{T}$ allele had a lower frequency of nausea. ${ }^{39}$

\section{Genetics of pharmacodynamics Cyclooxygenase I and 2}

Prostaglandin-endoperoxide synthase 1 and 2 (PTGS1 and PTGS2) are separate genes which encode cyclooxygenase 1 (COX)-1 and COX-2. ${ }^{11}$ Genetic variation in either of these enzymes can cause altered pharmacodynamic responses to NSAIDs.

Lee et al noted that certain SNPs are associated with altered expression of the PTGS2 transcript. ${ }^{40}$ In particular, a $\mathrm{G} \rightarrow \mathrm{C}$ polymorphism in the promoter region of the gene is associated with lower PTGS2 expression in individuals compared to those who inherit the homozygous major allele $(\mathrm{G} / \mathrm{G})$. Subjects with homozygous major allele reported lower pain intensities with rofecoxib treatment for 48 hours following surgery, compared to $\mathrm{G} / \mathrm{C}$ or $\mathrm{C} / \mathrm{C}$ subjects. This was not seen in those treated with ibuprofen. However, subjects with $\mathrm{G} / \mathrm{C}$ or $\mathrm{C} / \mathrm{C}$ genotypes reported decreased pain intensity with ibuprofen treatment at 48 hours following surgery, compared to $\mathrm{G} / \mathrm{G}$ patients. This was not seen in subjects treated with rofecoxib. This is presumably because G/G patients have increased PTGS2 and increased COX-2 expression and therefore have an improved response to a COX-2 selective agent. On the other hand, patients who are heterozygous or homozygous for the minor allele $(\mathrm{G} / \mathrm{C}$ or $\mathrm{C} / \mathrm{C}$ genotype) may have reduced $\mathrm{COX}-2$ expression and therefore experience greater benefit from a nonselective NSAID such as ibuprofen.

\section{$\mu$-opioid receptor}

The gene encoding for the $\mu$-opioid receptor is known as OPRM1. A number of SNPs have been described in OPRM1, and the most well characterized of these is $\mathrm{A} 118 \mathrm{G} .{ }^{30}$ The $\mathrm{A} \rightarrow$ G nucleotide substitution is thought to result in higher binding affinity of beta-endorphins to the $\mu$-opioid receptor. ${ }^{11}$

Liu and Wang reported a prevalence of $31.3 \%$ of the AA (wild-type) genotype, $58.3 \%$ of the AG genotype, and $10.4 \%$ of the GG genotype. ${ }^{41}$ It has been suggested that the $\mathrm{G}$ allele for OPRM1 may provide some protection against pain. One study found that the minor allele $(G)$ was more likely to be present in a control group of opioid-naïve patients compared to patients with chronic pain treated with opioids. ${ }^{42}$ Another trial found that fentanyl requirements after cosmetic orofacial surgery were significantly reduced in patients carrying the OPRM1 minor allele variant. ${ }^{43}$

In the obstetric population, women with an A118G SNP, regardless of whether they are homozygous or heterozygous, have been demonstrated to have higher pressure pain thresholds than women with the wild-type allele. ${ }^{44}$ Another trial in the obstetric population found that women with the $G$ variant were more responsive to intrathecal fentanyl. ${ }^{45}$

Other studies indicate that patients carrying the GG allele required higher opioid doses to achieve adequate pain relief. ${ }^{46,47}$ One trial examined the $\mu$-opioid receptor genotypes of 207 cancer patients who had been treated with a stable dose of morphine over a period of at least 3 days. The investigators found that OPRM1 AA patients required an average morphine dose of $112 \mathrm{mg}$ over 24 hours, whilst the AG group required an average dose of $132 \mathrm{mg}$ and the GG group required an average of $216 \mathrm{mg}$ over the same time period. ${ }^{47}$ Although these data appear to contradict earlier studies, ${ }^{42-45}$ a possible explanation is that fentanyl has a higher binding affinity (threefold) compared to morphine and beta-endorphins for the $\mu$-opioid receptor. An increase in the binding affinity of beta-endorphins for the receptor may provide greater competition for morphine, thus resulting in higher doses required to displace beta-endorphin from the $\mu$-opioid receptor. At the very least, it suggests that people with A118G variant have different responses to opioids compared to those with the wild-type allele.

\section{$\kappa$-opioid receptor and $\delta$-opioid receptor}

The genes OPRK1 and OPRD1 encode the $\kappa$-opioid and $\delta$-opioid receptor, respectively. Variations in OPRK1 and OPRD1 expression have been associated with dependence and addiction to various substances, including alcohol, opioids, heroin, and cocaine. ${ }^{48,49}$ Other allelic variations such as the $36 \mathrm{G}>\mathrm{T}$ substitution have been associated with increased postoperative and chronic pain. ${ }^{12}$

\section{Catechol-O-methyl transferase}

The catechol-O-methyl transferase (COMT) enzyme is responsible for the breakdown of biologically active catecholamines, such as dopamine, noradrenaline, and adrenaline. These are involved in numerous physiological processes, including the modulation of pain. Several polymorphisms have been identified within the COMT gene. The most widely studied variant is $158 \mathrm{Met}$, where a $\mathrm{G}$ to A nucleotide substitution at codon 158 results in an amino acid change from valine to methionine. ${ }^{11}$ Trials have demonstrated patients with Met/ 
Met genotype have lower morphine requirements than those with a Val/Val expression. ${ }^{47,50,51}$ An interesting trial in children postadenotonsillectomy demonstrated that the presence of any number of COMT SNPs, including 158Met, was associated with a threefold greater likelihood of analgesic intervention compared to children who were homozygotes for major alleles. ${ }^{52}$ Children with SNPs were also more likely to have increased pain postoperatively using the Face, Legs, Activity, Cry, Consolability (FLACC) score.

\section{Psychology and pain}

The biopsychosocial model is a widely utilized treatment approach, particularly in patients with chronic pain. Psychological factors are intrinsically linked with the perception of pain as well as the ability to cope and response to different treatment modalities. A recent study published by Kuhnen et al looked at correlation between personality factors and the presence of the 5-HTTLPR short and long allele. ${ }^{53}$ They compared the homozygous long allele (LL) and short allele (SS) with the heterozygous (SL). Their results showed that patients with SL and SS genotypes demonstrated more neurotic behavior, levels of anxiety, and self-doubt and were more prone to negative emotions. The inability to cope with negative emotions has been shown to correlate with exacerbated pain sensitivity and emotional magnification of pain or "catastrophizing". ${ }^{2}$

\section{Serotonergic system}

The serotonergic (5HT) system is involved in the modulation of depression. Serotonin is a monoamine neurotransmitter that has been known to act synergistically with analgesic agents to reduce pain. Furthermore, it is well known that depression and anxiety have a significant impact on the chronic pain experience and functional capability. ${ }^{54} \mathrm{~A}$ recent study of the 5HTR2A gene in patients undergoing lower back surgery found significantly higher depression scores with postoperative pain in patients who were carrying at least one A allele of the 5HTR2A $1438 \mathrm{~A} / \mathrm{G} .{ }^{55}$ Women with certain alleles (5HTR1A-G and 5HTR2A-A) were also found to have lower levels of postoperative functioning and higher Beck Depression Inventory scores. ${ }^{55}$ Another trial found a significant difference in the analgesic effect between individuals with low expression of the serotonin transporter (5HTT) compared to those who were homozygous for high transporter expression. ${ }^{56}$ Patients with chronic pain are at risk of developing depression and many will respond to antidepressant therapy and psychological support. Knowledge of an increased genetic tendency toward depression may encourage a clinician to involve a psychologist or psychiatrist earlier and promote more effective management of their pain.

\section{Other potential drug targets}

There are promising areas of research under way which may one day be incorporated into pain management. Single-gene pain disorders have been identified which can offer interesting insights. ${ }^{57}$ There is ongoing research into hereditary conditions of pain insensitivity or lack of pain sensation that has exciting potential for perioperative pain management. ${ }^{58,59}$ Black mamba venom has been shown to completely abolish pain by targeting acid-sensing ion channels and may offer new potential targets for future analgesic agents. ${ }^{60}$

\section{Genome-wide association studies}

A genome-wide association study or whole-genome association study is an examination of the many common genetic variants in different individuals to determine whether a variant (usually an SNP) is associated with a particular trait. To date, there have been no genome-wide association studies in the field of pain medicine.

\section{Future directions and challenges}

Successful pain management requires the provision of analgesia without excessive adverse effects. Clinicians who treat pain have noted that the response to medications, particularly opioids, can vary in the clinical setting by as much as 40-fold. ${ }^{12}$ Pharmacogenomics may help to explain some of the variability in response and provide guidance as to the most effective analgesic medication and the optimal dosage.

Despite the exciting possibilities pharmacogenomics has to offer, there are many hurdles to overcome before it becomes part of routine clinical practice. Although there is an increasing body of evidence that suggests genetic variation plays a role in the development of pain and response to analgesia, our understanding remains limited, and there is a lack of high-quality trials and genome-wide association studies. ${ }^{6,57}$ The overall effects of analgesic medications are not monogenic, but are influenced by multiple genes affecting multiple pathways of drug metabolism, distribution, and end organ effects. ${ }^{4}$ We have also yet to establish whether patient outcomes will improve due to genotyping prior to commencement of drug therapy. ${ }^{5}$ Cost-effectiveness also needs to be considered. At this stage, screening for genomic variants remains expensive and difficult to access.

Currently, personalized medicine is not feasible as a routine part of pain management. The incorporation of pharmacogenomics into other areas of clinical medicine has been 
proven to be effective, and there is increasing evidence to support its use. Unfortunately, though there is great potential for the use of pharmacogenetics to untangle the complexities of pain management, there is need for further research, such as genome-wide association studies. The hope is that one day it will enable pain physicians to streamline their prescribing patterns, allowing them to select the right drug, at the right dose, for the right patient.

\section{Disclosure}

The authors report no conflicts of interest in this work.

\section{References}

1. Nielsen LM, Olesen AE, Branford R, Christrup LL, Sato H, Drewes AM. Association between human pain-related genotypes and variability in opioid analgesia: an updated review. Pain Pract. 2015;15(6):580-594.

2. American Pain Society. Pain research funding inadequate in the face of soaring incidence and treatment costs [press release]. Chicago, IL: American Pain Society; 2013 [May 10]. Available from: http://americanpainsociety.org/about-us/press-room/pain-researchfunding-inadequate. Accessed May 2, 2015.

3. National Pain Summit Initiative. National Pain Strategy: Pain Management for All Australians. National Pain Summit Initiative; 2010. Available from: http://www.painaustralia.org.au/images/pain_australia/NPS/National\%20 Pain\%20Strategy\%202011.pdf. Accessed May 16, 2015.

4. Evans WE, Relling MV. Pharmacogenomics: translating functional genomics into rational therapeutics. Science. 1999;286(5439): 487-491.

5. Pirmohamed M. Pharmacogenetics and pharmacogenomics. Br J Clin Pharmacol. 2001;52(4):345-347.

6. Rollason V, Samer C, Piguet V, Dayer P, Desmeules J. Pharmacogenetics of analgesics: toward the individualization of prescription. Pharmacogenomics. 2008;9(7):905-933.

7. Browne EA. The inheritance of an intrinsic abnormality of the red blood cell predisposing to drug-induced hemolytic anemia. Johns Hopkins Med J. 1957;101:115-118.

8. Ingelman-Sundberg M. Genetic polymorphisms of cytochrome P450 2D6 (CYP2D6): clinical consequences, evolutionary aspects and functional diversity. Pharmacogenomics J. 2005;5(1):6-13.

9. Frazer KA. Decoding the human genome. Genome Res. 2012;22(9): 1599-1601.

10. Stamer UM, Zhang L, Stüber F. Personalized therapy in pain management: where do we stand? Pharmacogenomics. 2010;11(6):843-864.

11. Kapur BM, Lala PK, Shaw JL. Pharmacogenetics of chronic pain management. Clin Biochem. 2014;47(13-14):1169-1187.

12. Trescot AM, Faynboym S. A review of the role of genetic testing in pain medicine. Pain Physician. 2014;17(5):425-445.

13. Foster A, Mobley E, Wang Z. Complicated pain management in a CYP450 2D6 poor metabolizer. Pain Pract. 2007;7(4):352-356.

14. Zhou SF, Liu JP, Chowbay B. Polymorphism of human cytochrome P450 enzymes and its clinical impact. Drug Metab Rev. 2009;41(2): 89-295.

15. Armstrong SC, Cozza KL. Pharmacokinetic drug interactions of morphine, codeine, and their derivatives: theory and clinical reality, Part II. Psychosomatics. 2003;44(6):515-520.

16. Bernard S, Neville KA, Nguyen AT, Flockhart DA. Interethnic differences in genetic polymorphisms of CYP2D6 in the US population: clinical implications. Oncologist. 2006;11(2):126-135.

17. Madadi P, Ross CJ, Hayden MR, et al. Pharmacogenetics of neonatal opioid toxicity following maternal use of codeine during breastfeeding: a case-control study. Clin Pharmacol Ther. 2009;85(1):31-35.
18. Orliaguet G, Hamza J, Couloigner V, et al. A case of respiratory depression in a child with ultrarapid CYP2D6 metabolism after tramadol. Pediatrics. 2015;135(3):e753-e755.

19. Kirchheiner J, Nickchen K, Bauer M, et al. Pharmacogenetics of antidepressants and antipsychotics: the contribution of allelic variations to the phenotype of drug response. Mol Psychiatry. 2004;9(5): $442-473$.

20. Visser LE, van Schaik RH, van Vliet M, et al. Allelic variants of cytochrome P450 2C9 modify the interaction between nonsteroidal anti-inflammatory drugs and coumarin anticoagulants. Clin Pharmacol Ther. 2005;77(6):479-485.

21. García-Martín E, Martínez C, Ladero JM, Agúndez JA. Interethnic and intraethnic variability of CYP2C8 and CYP2C9 polymorphisms in healthy individuals. Mol Diagn Ther. 2006;10(1):29-40.

22. Rosemary J, Adithan C. The pharmacogenetics of CYP2C9 and CYP2C19: ethnic variation and clinical significance. Curr Clin Pharmacol. 2007;2(1):93-109.

23. Pilotto A, Seripa D, Franceschi M, et al. Genetic susceptibility to nonsteroidal anti-inflammatory drug-related gastroduodenal bleeding: role of cytochrome P450 2C9 polymorphisms. Gastroenterology. 2007;133(2):465-471.

24. Lundblad MS, Ohlsson S, Johansson P, Lafolie P, Eliasson E. Accumulation of celecoxib with a 7-fold higher drug exposure in individuals homozygous for CYP2C $9 * 3$. Clin Pharmacol Ther. 2006;79(3):287-288.

25. Stempak D, Bukaveckas BL, Linder M, Koren G, Baruchel S. Cytochrome P450 2C9 genotype: impact on celecoxib safety and pharmacokinetics in a pediatric patient. Clin Pharmacol Ther. 2005;78(3):309-310.

26. Carbonell N, Verstuyft C, Massard J, et al. CYP2C9*3 loss-of-function allele is associated with acute upper gastrointestinal bleeding related to the use of NSAIDs other than aspirin. Clin Pharmacol Ther. 2010;87(6):693-698.

27. Trescot AM. Genetics and implications in perioperative analgesia. Best Pract Res Clin Anaesthesiol. 2014;28(2):153-166.

28. Wadelius M, Chen LY, Lindh JD, et al. The largest prospective warfarintreated cohort supports genetic forecasting. Blood. 2009;113(4): 784-792.

29. Campa D, Gioia A, Tomei A, Poli P, Barale R. Association of ABCB1/ MDR1 and OPRM1 gene polymorphisms with morphine pain relief. Clin Pharmacol Ther. 2008;83(4):559-566.

30. Cohen M, Sadhasivam S, Vinks AA. Pharmacogenetics in perioperative medicine. Curr Opin Anaesthesiol. 2012;25(4):419-427.

31. Meineke I, Freudenthaler S, Hofmann U, et al. Pharmacokinetic modelling of morphine, morphine-3-glucuronide and morphine-6-glucuronide in plasma and cerebrospinal fluid of neurosurgical patients after short-term infusion of morphine. Br J Clin Pharmacol. 2002;54(6): 592-603.

32. Zwisler ST, Enggaard TP, Noehr-Jensen L, et al. The antinociceptive effect and adverse drug reactions of oxycodone in human experimental pain in relation to genetic variations in the OPRM1 and ABCB1 genes. Fundam Clin Pharmacol. 2010;24(4):517-524.

33. Park HJ, Shinn HK, Ryu SH, Lee HS, Park CS, Kang JH. Genetic polymorphisms in the ABCB1 gene and the effects of fentanyl in Koreans. Clin Pharmacol Ther. 2007;81(4):539-546.

34. Kesimci E, Engin AB, Kanbak O, Karahalil B. Association between $\mathrm{ABCB} 1$ gene polymorphisms and fentanyl's adverse effects in Turkish patients undergoing spinal anesthesia. Gene. 2012;493(2):273-277.

35. Sadhasivam S, Chidambaran V, Zhang X, et al. Opioid-induced respiratory depression: ABCB1 transporter pharmacogenetics. Pharmacogenomics J. 2015;15(2):119-126.

36. De Gregori S, De Gregori M, Ranzani GN, Allegri M, Minella C, Regazzi M. Morphine metabolism, transport and brain disposition. Metab Brain Dis. 2012;27(1):1-5.

37. van Dorp EL, Morariu A, Dahan A. Morphine-6-glucuronide: potency and safety compared with morphine. Expert Opin Pharmacother. 2008;9(11):1955-1961. 
38. Matic M, Norman E, Rane A, et al. Effect of UGT2B7 -900G>A $(-842 \mathrm{G}>\mathrm{A}$; rs7438135) on morphine glucuronidation in preterm newborns: results from a pilot cohort. Pharmacogenomics. 2014;15(12): 1589-1597.

39. Fujita K, Ando Y, Yamamoto W, et al. Association of UGT2B7 and $\mathrm{ABCB} 1$ genotypes with morphine-induced adverse drug reactions in Japanese patients with cancer. Cancer Chemother Pharmacol. 2010;65(2):251-258.

40. Lee YS, Kim H, Wu TX, Wang XM, Dionne RA. Genetically mediated interindividual variation in analgesic responses to cyclooxygenase inhibitory drugs. Clin Pharmacol Ther. 2006;79(5):407-418.

41. Liu YC, Wang WS. Human mu-opioid receptor gene A118G polymorphism predicts the efficacy of tramadol/acetaminophen combination tablets (ultracet) in oxaliplatin-induced painful neuropathy. Cancer. 2012;118(6):1718-1725.

42. Janicki PK, Schuler G, Francis D, et al. A genetic association study of the functional $\mathrm{A} 118 \mathrm{G}$ polymorphism of the human mu-opioid receptor gene in patients with acute and chronic pain. Anesth Analg. 2006;103(4): 1011-1017.

43. Fukuda K, Hayashida M, Ide S, et al. Association between OPRM1 gene polymorphisms and fentanyl sensitivity in patients undergoing painful cosmetic surgery. Pain. 2009;147(1-3):194-201.

44. Fillingim RB, Kaplan L, Staud R, et al. The A118G single nucleotide polymorphism of the mu-opioid receptor gene (OPRM1) is associated with pressure pain sensitivity in humans. J Pain. 2005;6(3):159-167.

45. Landau R, Kern C, Columb MO, Smiley RM, Blouin JL. Genetic variability of the mu-opioid receptor influences intrathecal fentanyl analgesia requirements in laboring women. Pain. 2008;139(1):5-14.

46. Zhang Y, Wang D, Johnson AD, Papp AC, Sadée W. Allelic expression imbalance of human mu opioid receptor (OPRM1) caused by variant A118G. J Biol Chem. 2005;280(38):32618-32624.

47. Reyes-Gibby CC, Shete S, Rakvåg T, et al. Exploring joint effects of genes and the clinical efficacy of morphine for cancer pain: OPRM1 and COMT gene. Pain. 2007;130(1-2):25-30.

48. Butelman ER, Yuferov V, Kreek MJ. א-opioid receptor/dynorphin system: genetic and pharmacotherapeutic implications for addiction. Trends Neurosci. 2012;35(10):587-596.
49. Crist RC, Ambrose-Lanci LM, Vaswani M, et al. Case-control association analysis of polymorphisms in the $\delta$-opioid receptor, OPRD1, with cocaine and opioid addicted populations. Drug Alcohol Depend. 2013;127(1-3):122-128.

50. Rakvåg TT, Klepstad P, Baar C, et al. The Val158Met polymorphism of the human catechol-O-methyltransferase (COMT) gene may influence morphine requirements in cancer pain patients. Pain. 2005;116(1-2):73-78.

51. Sadhasivam S, Chidambaran V. Pharmacogenomics of opioids and perioperative pain management. Pharmacogenomics. 2012;13(15): 1719-1740.

52. Sadhasivam S, Chidambaran V, Olbrecht VA, et al. Genetics of pain perception, COMT and postoperative pain management in children. Pharmacogenomics. 2014;15(3):277-284.

53. Kuhnen CM, Samanez-Larkin GR, Knutson B. Serotonergic genotypes, neuroticism, and financial choices. PloS One. 2013;8(1):e54632.

54. Holmes A, Christelis N, Arnold C. Depression and chronic pain. Med J Aust. 2013;199(6 Suppl):S17-S20.

55. Lebe M, Hasenbring MI, Schmieder K, et al. Association of serotonin$1 \mathrm{~A}$ and -2A receptor promoter polymorphisms with depressive symptoms, functional recovery, and pain in patients 6 months after lumbar disc surgery. Pain. 2013;154(3):377-384.

56. Kosek E, Jensen KB, Lonsdorf TB, Schalling M, Ingvar M. Genetic variation in the serotonin transporter gene (5-HTTLPR, rs25531) influences the analgesic response to the short acting opioid Remifentanil in humans. Mol Pain. 2009;5:37.

57. Mogil JS. Pain genetics: past, present and future. Trends Genet. 2012;28(6):258-266.

58. Axelrod FB, Gold-von Simson G. Hereditary sensory and autonomic neuropathies: types II, III, and IV. Orphanet J Rare Dis. 2007;2:39.

59. Klein CJ, Wu Y, Kilfoyle DH, et al. Infrequent SCN9A mutations in congenital insensitivity to pain and erythromelalgia. J Neurol Neurosurg Psychiatry. 2013;84(4):386-391.

60. Diochot S, Baron A, Salinas M, et al. Black mamba venom peptides target acid-sensing ion channels to abolish pain. Nature. 2012;490(7421): $552-555$.
Journal of Pain Research

\section{Publish your work in this journal}

The Journal of Pain Research is an international, peer-reviewed, open access, online journal that welcomes laboratory and clinical findings in the fields of pain research and the prevention and management of pain. Original research, reviews, symposium reports, hypothesis formation and commentaries are all considered for publication.

\section{Dovepress}

The manuscript management system is completely online and includes a very quick and fair peer-review system, which is all easy to use. Visit http://www.dovepress.com/testimonials.php to read real quotes from published authors. 